\title{
Vulnerability Assessment of Agri-ecotourism Communities as Influenced by Climate Change
}

\author{
Hanilyn A. Hidalgo \\ ${ }^{\#}$ College of Economics and Management, Central Bicol State University of Agriculture, Pil 4415, Camarines Sur, Philippines \\ E-mail: hanilyn77@yahoo.com, hanilyn77@gmail.com
}

\begin{abstract}
The growth of tourism in the Philippines can be largely attributed to nature-based destinations but communities in these areas largely depend on farming and fishing to sustain their day-to-day needs. The need to capacitate the community's social and human capital in addressing climate change impacts to their livelihood, properties and natural environment is deemed necessary to lessen their vulnerability issues in the management of agriecotourism destinations. The study aimed to 1.) characterize and rank hazards that are likely to affect the nature-based tourism communities, 2 .) describe the nature-based tourism communities' current sensitivity and exposure to climate stresses; and 3.) estimate future vulnerability and risks of nature-based tourism communities. Three agri-ecotourism communities were selected using five criteria such as attraction uniqueness, hazard type, risk level, tourism dependency and market potential. The areas were subjected to tourism vulnerability case assessment focusing on services and energy; human health; food, security, water and agriculture; business and continuity; and biodiversity and culture. Calaguas Island's top hazards are typhoon, drought and strong wind. Pecuaria Farm's main hazards are drought, rat infestation and grass fire while Bulusan Lake's major hazards are heavy rains and ash falls brought by volcanic eruption. Generally, vulnerability is high in the human health, services and energy sectors of tourism. The vulnerability of the three agri-ecotourism sites was intensified by factors that merely characterize the kind of community they have: a) high marketing dependency, b) poor political will, c) low level of awareness and preparedness, d) poor farming practices and e) lack of tourism-related livelihood options. Destinations with functioning agricultural areas are the most affected sites due to an estimated increase in the temperature and increase in rainfall precipitations. Poverty remains to be the major factor why vulnerability is high.
\end{abstract}

Keywords - agri-ecotourism communities; vulnerability assessment; climate change; Philippines

\section{INTRODUCTION}

The Philippines' National Statistical Coordination Board (NSCB) recently reported that tourism remains to be one of its major economic growth drivers. For the past years, tourism has significantly contributed to country's foreign exchange earnings, investments and employment. In 2011, about 10 per cent of the employed population (3.9 million persons) and 6 per cent of the gross domestic product (P571.3 billion) are accounted from tourism sector. But with the Association of Southeast Asian Nations (ASEAN) full economic integration by 2015, the Department of Tourism (DOT) projects a relatively higher contribution to the economy in the next two years.

The growth of tourism is in the Philippines can be largely attributed to nature-based destinations. In fact, the Asean Tourism Marketing Strategy 2012-2015 focused on the development of four tourism niche products - nature, cultural and heritage, community, and cruise and river-based tourism. While some of the potential eco-adventures are somewhat seen to generate revenues and employment in rural communities, many people still depend on farming and fishing to sustain their day-to-day needs. This holds true for many ecotourism sites due to seasonality of market as influenced by climate-related factors such as temperature, wind and sunshine.

While the DOT and the Department of Environment and Natural Resources (DENR) are pushing for natural resource management as a means to enhance livelihood activities and sustainably manage both natural and cultural resources in the community, issues on climate change impacts must be properly addressed to improve the resiliency of both the potential community-based tourism sites and, in particular, the tourism-dependent communities. A clear understanding of the factors that contribute to the society's vulnerability can help in developing effective adaptive strategies.

Poverty is said to be one of the major causes of deaths linked with natural disasters. Poor people have fewer accesses to financial and physical resources which make them susceptible to economic adversity and natural disasters. 
They have very limited information on how they could reduce the risks brought by extreme hazards.

The latest survey in the country revealed that fisherfolk has the highest poverty incidence followed by farmers at 41 percent and 37 percent, respectively. Accordingly, the figures are manifestation of a slow productivity and growth in the agriculture sector. Yet despite of this, more than one million Filipinos depend on the sector. Poverty forces people to extensively exploit the natural resources which could result to an increased vulnerability from deforestation and soil degradation effects.

It is quite alarming to note that Bicol Region has the highest concentration of poor among the fishermen at 56.5 per cent and 47.4 percent among the farmers. Though these figures do not essentially mirror the region's contribution to agricultural production, they still exhibit economic depression to farming communities. However, as global tourism shift to a more sustainable development programs, many remote areas in rural provinces will be benefited. The inclusion of Camarines Sur, Albay and Sorsogon in the Philippine tourism map is an indication that development of nature-based tourism in the region has already been initiated. Ecotourism has already been mainstreamed in communities such as Donsol, Sorsogon, Caramoan Islands, Mt. Isarog Natural Park and Mayon Volcano Natural Park while a few farmers gradually transform their conventional farms into agritourism destinations [1].

With the evolution of nature-based tourism such as agritourism and ecotourism in the rural areas, there is really a need to capacitate the community's social and human capital in addressing climate change impacts to their livelihood, properties and natural environment. Preventing future damages can be seen as an investment and savings that are worth keeping for better communal projects. In the same way, a long-term poverty reduction plan cannot be effective if the community remains to be vulnerable from natural disasters.

The objectives of the study were to: 1) characterize and rank hazards that are likely to affect the nature-based tourism communities; 2) describe the nature-based tourism communities' current sensitivity and exposure to climate stresses; and 3) estimate future vulnerability and risks of nature-based tourism communities

The US State Department described the Philippines as a volcano-typhoon-flood-and-earthquake prone country [2]. This was validated in the Intergovernmental Panel for Climate Change 2007 report disclosing Philippines as among the major global climate host spots where impacts from rise in sea levels, temperature rise, changes in rainfall patterns and increase in frequency and intensity of extreme weather events could affect major sectors such as agriculture and tourism [3].

The presence of high poverty incidence in many typhoonprone areas, damage became too expensive and recovery was difficult. In 2011where ten destructive typhoons entered the country, total damages from infrastructure and agriculture in Bicol and Visayas was already pegged at PhP25.2 billion. Loss and damages could have been reduced if the community has a high disaster risk management capacity. People who are mostly affected are the farmers, fisherfolk, micro-entrepreneurs and informal sectors [4].
But despite this alarming report, visitor arrival in the Philippines, for the last three years, has been on a growing trend. Apparently, tourism posted one of the largest contributors to the 7.1 percent reported growth rate in Bicol economy [5].

The Food and Agriculture Organization (FAO) defines vulnerability as a condition determined by physical, social, economic and environmental factors or processes that reduce people's ability to prepare for, withstand or respond to a hazard. The level of vulnerability of a society to a specific extreme natural phenomenon is determined by the potential damage caused by the natural phenomenon [8].

Climate change could largely affect nature-based tourism destinations. The impact of these changes may influence visitor's experience especially if the destination is mainly dependent on its natural attraction. The accessibility of the site may be affected by weather events and climatic trends. Transport by sea and air are the most vulnerable. Outdoor activities and events are often affected by extreme weather conditions. Consequentially, this impairs visitor's enjoyment and safety. Furthermore, changes in weather patterns may affect the attractiveness of a destination. Beach ecotourism is at its best during sunny days. Longer period of days with rain will distress its appeal and visitor's experience. However, not all climate change effects bring inconvenience and difficulty. In the vulnerability assessment of Sorsogon City, the increase in temperature resulted to increase in tourism facilities such as resorts and swimming pools in the city.

Among ecotourism destinations, Wall (2007) claimed that mountains and coasts are likely to be more vulnerable than those which depend on cultural or historical attractions. He believed that coastal areas seem to require thorough attention since these types of destinations have a higher susceptibility to changing water levels [9]. Recreational activities are enhanced with the presence of water. Hence, if this falls short, tourism will need to compete with other industries in terms of water use.

In community-based tourism, vulnerability increases when there is a high dependency on tourism as a primary source of livelihood; high seasonality as affected by climaterelated factors; intense reliance on the marketing strategy of international travel operators and agent; and susceptibility of destination images to unconstructive exposures.

In the Destination Vulnerability Assessment study in Khao Lak, Thailand, the community's vulnerability was affected by limited access to liquid financial assets and low levels of insurance; inadequate hazard awareness and preparedness; and weaknesses in governance, structures and processes. Auspiciously, people's recovery from tsunami was strengthened by strong family support and social networks. The disaster became a driving force to the business owners to bolster their entrepreneurial skills.

Climate change impact studies in nature-based tourism destinations in the Philippines particularly in Bicol are in short supply. Much of the studies are focussed on farming and fishing activities.

The burgeoning of nature-based tourism destinations in the region will pave the way for enhancing the agriculture sector through value additions to existing products and services. Furthermore, the formation of an alliance such as 
the Albay-Masbate-Sorsogon (ALMASOR) that will harness the combined resource potentials of the provinces of Albay, Masbate and Sorsogon that will link the initially established Catanduanes-Camarine Sur- Camarines Norte Tourism Link (CCTL); and the aggressive marketing of tourism alliance (Metro Naga X) formed in the fifteen municipalities under the Metro Naga Development Council will certainly provide a significant impact to the number of tourist arrivals in the entire region.

Yet, the communities at stake remain to be susceptible to climate change impacts. Capacity-building activities should not be limited to skills enhancement but more particularly on adjustments needed to make to increase their viability and reduce their vulnerability.

\section{MethodOLOGY}

\section{A. Research Design and Sampling}

Case study method was used in assessing the vulnerability of nature-based tourism in Bicol Region. Each tourism site was studied thoroughly where aspects of tourism industry were subjected to vulnerability analysis.

In the study, nature-based tourism sites include agritourism and ecotourism destinations within the Bicol region. The sites are under a community-based undertaking. "Community-based tourism is a tourism that takes environmental, social and cultural sustainability into account. It is managed and owned by the community, for the community, with the purpose of enabling visitors to increase their awareness and learn about the community and local ways of life"

The study adopted a purposive sampling method. Three agri-ecotourism sites based from a set of criteria were selected. The criteria used are: 1) Uniqueness of product/service/attraction; 2) Type of hazard; 3) Level of risk; 4) Dependency on tourism; and 5) Market potential

There were six pre-identified community-based agriecotourism sites. These are Pecuaria Farm of Pecuaria Development Cooperative, Inc. in Lanipga, Bula, Camarines Sur; Paniman Beach in Caramoan, Camarines Sur; Calaguas Island in Vinzons, Camarines Norte; Pineapple farms in Daet, Camarines Norte; Bulusan Lake in Bulusan, Sorsogon and Donsol Beach in Donsol, Sorsogon. From these areas, three sites were selected based from the five criteria of equal weights. With a total score of 100, the top highest sites were selected. These sites include Calaguas Island, Pecuaria Farm and Bulusan Lake. Although Donsol seems to have the highest rate for uniqueness in attraction and tourism dependency due to its Butanding interaction activity, the area has relatively low level of risks and hazards which can probably be attributed to the numerous tourism development support provided by various local and international agencies and organizations.

In assessing the vulnerability of each community, respondents were selected randomly. A total of 147 household representatives were interviewed from the three areas.

\section{B. Data Gathering and Analysis}

The study employed survey method, key informant interviews, participatory rapid appraisal (PRA), and ground thruthing. Survey method was used to select the case sites that will fall under the predetermined criteria. Key informant interviews was adopted to determine from technical experts and stakeholders the existing and potential hazards and impacts of the sites selected. PRA to the selected communities was used to assess the vulnerability of the people and their resources. Data gathered were validated through ground truthing technique. Ground-truthing refers to a method of validating data with input from community members to ensure outcomes accurately reflect conditions in the community.

Qualitative ranking was employed in identifying the hazards in terms of potential impacts such as frequency and severity. The table below shows the scale of ranking:

TABLE I

SCALE OF RANGKING

\begin{tabular}{|c|c|c|c|}
\hline Scale & Frequency & Severity & Overall Ranking \\
\hline 1 & Highly likely & Catastrophic & Very high \\
\hline 2 & Likely & Critical & High \\
\hline 3 & Possible & Limited & Medium \\
\hline 4 & Unlikely & Negligible & Low \\
\hline
\end{tabular}

The vulnerability factors used in assessing within the context of tourism industry are: services and energy, human health, food security, water and agriculture, business continuity and biodiversity. The vulnerability factors will be assessed using a table that will seek to answer the community's condition and potential impact

\section{RESULT AND DISCUSSION}

\section{A. Hazard Characterization}

\section{1) Calaguas Island}

Typhoon, drought, strong wind, sea level rise, and rainfall are the hazards which significantly impact the affected communities. As a result, loss of income, casualties, and damage to shelter occur. Community folks recalled that the most damaging typhoon that occurred in their island was Typhoon Rosing in the last quarter of 1995. This typhoon which has a gustiness of $260 \mathrm{kph}$ ravaged Calaguas, It was the most destructive typhoon so far in the history of the place. The coastal community experienced flooding and houses were washed-out. Two kids died from the disaster.

TABLE II

HAZARDS IN CALAGUAS ISLAND

\begin{tabular}{|l|c|c|c|}
\hline \multicolumn{1}{|c|}{ Hazard } & Severity & Frequency & Level \\
\hline Typhoon & 1 & 1 & Very high \\
\hline Drought & 1 & 1 & Very high \\
\hline Strong wind & 1 & 1 & Very high \\
\hline Sea level rise & 1 & 4 & Very high \\
\hline
\end{tabular}

Drought happens during the summer season. There is shortage in food supply during extreme droughts. The people could not plant vegetables and root crops due to arid soil. People often call this "hard life season" before tourism was developed in the island. On the other hand, the fishing industry is affected by strong wind which happens every month except on April and May. It would be too dangerous for fishing boats to catch fish because of high waves which 
height is tantamount to a three-storey building. No boat could leave nor enter the island when strong wind occurs. This also indicates food scarcity in the community. Incidentally, there are also reported cases of cyanide and illegal fishing activities in Calaguas.

The affected families transfer to evacuation centers and place their valuables in plastic containers or sacks; they also make it a point to be updated on the weather situation through the radio. The drought and big waves force the family to look for alternative sources of income like fishing, working in other areas, or the men earning as construction workers.

\section{2) Pecuaria Farm}

As an integrated farm enterprise engaged in agricultural production particularly of organic rice and organic inputs, PDCI is exposed to various hazards like typhoons, flooding, grass fire, drought, strong wind, low temperature, and rat infestation. These hazards result to loss of income, some casualties, damage to crops and livelihood, and partial or total damage to shelter.

In the event of typhoons, the residents usually listen to the radio to make sure every member of the family is safe and move to evacuation centers when necessary. During droughts, the farmer looks for alternative jobs to sustain their need for food. They also plant root crops or other droughtresistant crops. In case of grass fire, they manually extinguish the fire. Lastly, for rat infestation, they resort to rat poisoning and traps.

TABLE III

HAZARDS IN PECUARIA FARM

\begin{tabular}{|l|c|c|c|}
\hline \multicolumn{1}{|c|}{ Hazard } & Severity & Frequency & Level \\
\hline Drought & 1 & 1 & Very high \\
\hline Rat infestation & 1 & 2 & Very high \\
\hline Grass fire & 2 & 1 & Very high \\
\hline Strong wind & 2 & 2 & Very high \\
\hline Flood & 4 & 1 & Very high \\
\hline Typhoon & 4 & 1 & Very high \\
\hline Erosion & 4 & 1 & Very high \\
\hline
\end{tabular}

\section{3) Bulusan Lake}

Some of the existing hazards in the Bulusan community are flood, rain fall, typhoon, landslide, volcanic eruption, ash falls, earthquake and drought. These hazards have substantial impact on the people, property and environment like loss of income, some casualties, damage to crops and livelihood, and damage to shelter.

TABLE IV

HAZARDS IN BULUSAN LAKE

\begin{tabular}{|l|c|c|c|}
\hline \multicolumn{1}{|c|}{ Hazard } & Severity & Frequency & Level \\
\hline Rainfall & 1 & 1 & Very high \\
\hline Ash falls & 1 & 3 & Very high \\
\hline Volcanic eruption & 2 & 3 & High \\
\hline Flood & 3 & 2 & High \\
\hline Typhoon & 3 & 2 & High \\
\hline Landslide & 3 & 3 & Medium \\
\hline Earthquake & 3 & 3 & Medium \\
\hline Drought & 4 & 3 & Low \\
\hline
\end{tabular}

Mount Bulusan or the Bulusan Volcano is one of the active volcanoes in the Philippines. The recorded total number of eruptions of the Bulusan volcano is about 15 times since 1885 . The most recent volcanic activity was noted last October of 2011 in Barangay San Roque wherein the ash fall lasted for an hour. Ash falls due to the volcanic eruption can be a health hazard to the community. It may cause or aggravate respiratory diseases. Rampant fish kill was also observed due to the high level of sulfur in the water and high temperature. Typhoon rarely occurs and flooding is not that much of a problem in the place because of the forest covered with abundant trees.

\section{B. Vulnerability}

1) Services and Energy: Calaguas is not prepared if there is a sudden increase in energy demand. So far, the community uses solar panels and generator as their sources of energy. The solar panels were donated to the community and only a few households enjoy the privilege of using such panel. The members of the community and the guests are not prepared if ever fire or other disasters happen. There is no standard emergency procedure which will guide everyone to know what to do. Barangay Mangcawayan is located within1 kilometer of the coastal area. There have been cases of storm surges in the past and it washed out many of the properties and sources of livelihood.

PDCI has low capacity (financially and supply-wise) in dealing with increase in energy demand due to these emergency situations. There are emergency procedures to follow in case there is fire, if lightning strikes, or if there is heat stress but these are not reviewed at all. Inadequacy in emergency devices was also noted. There are no firebreaks on the property and no lightning conductor in the roofing of its major facilities.

Carbon footprint within the communities has not been recorded. There are no programs or projects for carbon emission reduction but there are plans to implement the use of renewable energy. The facility is not heavily dependent on foreign tourists which mean lessened carbon pressures due to reduced number of passengers of long haul flights going to the Philippines.

2) Human Health: In Calaguas Island, no vector-borne diseases were reported although the integrity of the fresh water supply is somehow compromised and there is no hygienic waste facility. Tourists and staff are highly exposed to heat stress but were able to find a solution through the amenities offered to get away from the direct heat of the sun.

Heat stress has been experienced by the PDCI's staff since most of their activities are in the field and they are directly under the sun. There is no existing facility where the farmers or visitors can escape the heat to avoid heat stress.

There are no reports with regard to vector-borne diseases in Bulusan. Fresh water supply is abundant and there is no problem on the sewerage or storm water drain in the area. In terms of air quality, ash falls are potentially detrimental to those with respiratory disorder or diseases.

3) Food Security, Water, and Agriculture: There has been shortage of staple food in the past in Calaguas. The area is prone to dry spell conditions and water restrictions. There is 
no local produce available which could be purchased to support local producers and reduce food miles because Calaguas is mainly a coastal area.

PDCI is primarily involved in the production of agricultural commodities like rice, muscovado and poultry but there have been occasions when people experienced food shortage. The facility does not completely rely on imported produce although it also sources some of its produce from other areas. Currently, the local produce is sufficient and can very well support the local producers. Meanwhile, Bulusan has abundant local produce which continuously supports local producers and substantially reduces food miles. What are lacking though are the sufficient refrigeration facilities which are valuable for extensive food storage

4) Business and Continuity: Heat wave conditions or the threat of drought to the farmers spell disaster especially with water-dependent crops. PDCI cannot maintain its services and properly operate in the event of heavy drought since the area needs a substantial amount of water supply in growing its crops and running other operations. It is not as prepared to deal with massive water shortage.

5) Biodiversity and Culture: Storm surge and flooding can disrupt cultural tours, inundate some of the natural ecosystems, and result in coastal erosion which could potentially obliterate and or displace the sensitive dune vegetation leaving the coastal infrastructure vulnerable to external forces. The operation is not as reliant on conservation or biodiversity-based attraction. There have been reports on cases of cyanide and illegal fishing before. These activities will sooner or later destroy the balance of the ecosystem.

TABLE V

LEVEL OF TOURISM VULNERABILITY IN AGRIECOTOURISM COMMUNITIES

\begin{tabular}{|l|c|c|c|}
\hline \multicolumn{1}{|c|}{ Aspect } & Calaguas & Pecuaria & Bulusan \\
\hline Services and Energy & High & High & Low \\
\hline Human Health & High & High & High \\
\hline $\begin{array}{l}\text { Food Security, Water } \\
\text { and Agriculture }\end{array}$ & High & Low & Low \\
\hline Business Continuity & Low & High & Low \\
\hline Biodiversity and Culture & High & Low & Low \\
\hline
\end{tabular}

\section{Vulnerability Assessment}

The vulnerability of the three agri-ecotourism sites was intensified by factors that merely characterize the kind of community they have.

1) High marketing dependency: One of the challenges of a community-based site is its capability to market an intangible product - destination. With poor background in destination marketing concepts, these communities rely on government bureaus such as DOT, DTI and DA to promote their sites. Pecuaria Farm is managed by a cooperative of which its main business is producing and selling organic rice. The idea of selling the agritourism experience is far from their basic knowledge of selling rice. Hence, they resort to seek the assistance of DOT, DA and academe to formalize the establishment of an agritourism destination.
The DA and academe played a significant role in putting Pecuaria Farm in the circuit of educational tours of many farmers in the country. In fact, the marketing success of its organic rice was made possible through collaboration with a private sector and the government bureaus. Agritourism industry in the region has not been fully developed compared with ecotourism. What is unique with Pecuaria Farm is so far the type of production technology it employs in its rice fields. If this will be replicated in a cooler climate, in a nearer area, in a better landscape, with various options, then, the life stage of its "destination" product will be shortened if not supported with on-time and effective marketing strategies.

In the case of Calaguas Island, local travel operators were responsible in the promotion of the beach ecotourism in the island. The community does not know the attraction of the island and more so, does not know how to sell the place. Since 2009 when it was discovered by a travel operator, tourists started flocking the island during summer. From 10,000 tourists per year, it has now more than 15,000 tourists per year. Presently, the community is still dependent to the marketing efforts of the travel operators. Local employment to some tourism services became evident in the community. Travel operators and community have compromised for the price of the services rendered to tourists.

Among the three sites, Bulusan Lake has the most number of marketing supports from government and nongovernment organizations. With a good marketing niche in the ecotourism industry, the site has attracted both foreign and local tourists. It has even encouraged several investors to establish their own spring resorts near the lake. As a permanent tourism gem in the province, community can capitalize on this by developing complementary tourism activities in the site.

2) Poor political will: The presence of tourism development plans of the municipal government units with a DRRM plan indicate a strong political will to use agri-ecotourism as an economic driver for growth. Unfortunately, these were not seen among the three sites in case. A tourism plan should provide a blueprint of the area's development projects so to redirect proper use of resources without compromising other assets of the community. Republic Act 10121 known as Philippine Disaster Risk Reduction and Management Act of 2010 provides the legal basis of institutionalizing disaster plans in the local government levels. The law provides a mandatory establishment of DRRM operations center from national to the barangay level. The absence of any of these plans makes the community more vulnerable to mitigate, prepare for, respond to and recover from the effects of climate change hazards. Services and infrastructure systems that should supposedly address the climate change effects are not given appropriate attention and priority.

3) Low level of awareness and preparedness: Poor political will in the planning and implementation of a well-developed DRRM results to low level of awareness to climate change effects. This is further translated to incompatible practices in the language of sustainability principles. In Calaguas Island, for instance, the $1 \mathrm{~km}$ distance of residential housing from the shore was not observed by some folks. Forest 
denudation in the forms of illegal logging and burning as alternative source of income has aggravated flooding in some parts of the island and within the Bulusan Lake areas. The cutting of trees in Pecuaria and conversion to rice fields has produced flooding during heavy rains and typhoons. These and other farming practices that seems to be unsuitable to the changing climatic conditions are not given preferential consideration as part of mitigating the effects to the people's health and economic conditions. Meanwhile, the low level of preparedness can be measured by the lack of emergency procedures in the community-based agriecotourism sites. This was further strengthened by the lack of health facilities and evacuation centers owned by the community. Some even have to use other community's facilities during disasters. The lack of awareness and preparedness can also be attributed to the low level of education of the community. In Calaguas Island where most children only reach the elementary level of schooling, the people are not aware that they are situated in a potential tsunami area. Hence, the level of dependency to DRRM operation centers becomes high.

4) Poor farming practices: With few knowledge in mitigating and adapting to climate change effects, people resort to poor or probably wrong concept of sustainable farming. When productivity drops at the farm level, natural resource exploitation becomes the next option to feed the family. For more than a decade now, farming technologies have not reached many of the country's rural farmers. Some private farm input providers observed that Bicol's crop performance is slow compared to Isabela and Nueva Ecija. Accordingly, Bicolano farmers are not risky. Understandably, in a typhoon-prone area, it would be difficult to invest. At this point, farming technologies in crops, livestocks and poultry has not reached the island of Calaguas. Rootcrops became their staple food when the sea is rough. That is why they could not showcase any agricultural farm because of climate-smart agriculture technology gap. It is also for the same reason why Bulusan Lake farmers could not demonstrate a complementary farm activity in its ecotourism landscape.

5) Lack of tourism-related livelihood options: Readiness to tourism is yet to be embraced by the communities in case. Destinations should not only offer the physical attraction of the place but the culture and indigenous practices of the people. The communities in the three sites are neither aware nor prepared to sell their place. During the consultation with the people, they are not aware of the tourists' expectations. The trend in tourism has changed extensively from mere relaxation to educational. The 2013 ITB Travel Trends Report revealed that the new Asian tourists are more demanding in terms of quality and service. These tourists are more paying attention to adventurous and creative travel experiences which agri-ecotourism destinations can offer.

\section{Future Vulnerability and Risks of Agri-ecotourism Communities}

The geographic location and the socio-economic condition of the communities provide a general impression that many of the nature-based tourism sites in the rural areas are vulnerable to climate change. The study of Pulhin, et. al, proved that the higher the level of dependency to agricultural livelihood, the higher the vulnerability of the households. This further connotes that vulnerability can be reduced if poverty is addressed at the farm level.

In the context of tourism, climate change effects such as higher temperature, increased frequency and intensity of heavy rains, prolonged periods with no rain, heat waves and sea level rise will create impact, in a significant manner, to the lives of both the tourism service providers and to the tourists as well.

In the Climate Change Vulnerability Mapping in Southeast Asia of Yusuf and Francisco, Philippines is among the most vulnerable areas with typhoons, landslides, droughts and floods as its dominant hazards. The areas with the highest vulnerability are National Capital Region, Southern Tagalog, Cagayan Valley, Central Luzon, the Cordillera Administrative Region and Bicol Region. The Philippine Atmospheric Geophysical and Astronomical Services Administration (PAGASA) predicts that in the next five decades to come, Bicol provinces may be hotter by 1 degree Celsius and rainfall may continually increase its precipitation by at most 17 percent than the observed baseline year in 2000 .

1) Services and energy. Hotter temperature in a tropical climate area could result to an increase in demand for cooling facilities for agri-ecotourism sites. Tourism operators, thus, need to find energy-efficient ways to offer convenience without altering the concept of nature-based destinations. Higher temperature would also mean developing climate-smart agriculture technologies since many agricultural lands in the region depends on rain-fed production. In Pecuaria Farm and Calaguas Island where drought is considered a hazard, this is an added threat to their existing agricultural crops. The frequency of bush fires may increase at a level that could be detrimental to the main crops of the farm.

2) Human health: Heat exposure brought by the rising temperature may lead to increase in cases of vector-borne and water-borne diseases such as malaria and dengue. The Global Health Action Journal further revealed other significant health risks such as infectious diseases, undernutrition and mental stresses which may affect the productivity of workers and satisfaction of tourists especially to developing countries. With a very high vulnerability level to the three agri-ecotourism sites, the local DRRM plans should prioritize the access of health service facilities of these communities.

3) Food security, water and agriculture: In the ClimateSmart Agriculture Sourcebook of the Food and Agriculture Organization of the United Nations, studies revealed that areas which are economically vulnerable and food insecure are the ones most affected by the decrease in agricultural production and increase in the variability of production. Just a little change in temperature may alter the productivity of a crop. A drop in food production may consequently lead to malnutrition as an effect of climate change. This becomes a major problem to many nature-based destinations since majority of the community livelihood are dependent on agriculture. The slow onset of agriculture enhancement programs of the government may compromise sustainability 
with food security. That is why land conversion of agricultural and forest areas to tourism enhancement sites seem to become accepted as remedy to so-called agricultural productivity. Dry season will further aggravate the current state of the farmers. In Calaguas Island, for instance, when strong winds occur, there is no way a person can get food from the sea. If the temperature will further increase and extreme rainfall precipitation occurs, they could not simply plant basic vegetables in the field, this result to more malnourished people in the community.

4) Business Continuity: Hotter temperature will compel tourism operators to mitigate its effects to tourists by providing value-added services and infrastructures in order to stay in the business. Considered as an environmental threat in the industry, climate change may pave the way for more competitive services. The unique attraction of Calaguas Island and Bulusan Lake may entice first time visitors but without mitigating measures to combat heat stress in an island, repeat visits may be affected. Among the three sites, Bulusan Lake will not be affected by the temperature increase since the area is covered with forested zones. Pecuaria Farm is most likely affected and pressured to ensure the integrity of an agritourism concept due to the sensitivity of the farm to climate changes.

5) Biodiversity: Studies revealed that marine species were observed to be shifting to other areas at a rate of 45-59 $\mathrm{km} /$ decade. If this happens, then, extinction of certain species may occur in a particular destination. A reshuffling may happen to the world's flora and fauna species. The projected extinction rate for birds, mammals, frogs, reptiles, invertebrates, and plants in areas around the world at 0.8 degeree Celsius increase in temperature is estimated at 11-34 percent. How may it affect the tourism sector? The supposedly natural resources attraction could no longer be claimed by a certain site. An increase in temperature may also endanger coral reefs due to bleaching effect. Lakes are not spared since an increased evaporation rate due to high temperature may lower the lake levels and eventually alter the potential attraction of the site.

An increase in the frequency and intensity of short duration heavy rains may disrupt the tourism services as this cause localized flooding and may cause surface water pollution which may be detrimental to agricultural production. In the case of Pecuaria Farm where organic farming is strictly observed, water flow from different farm areas transfers the surface pollution from one farm to another. Flood waters are strong source of contaminants due to potential exposure to sewage, animal waste, heavy metals, pathogenic microorganisms, among other contaminants. In the US Food and Drug Administration policy on food safety, crops exposed to flood water are no longer fit to enter human food channels since they are considered adulterated. Destinations with functioning agricultural farms are the most affected sites because more likely what is being offered as food to tourists comes mainly from the farm itself.

Weather is a significant factor in determining a destination for a holiday. According to PAG-ASA, Sorsogon is predicted to experience more precipitation of rains than the rest of the provinces in the region. Notably, Sorsogon is popular for ecotourism destinations such as
Butanding Interaction in Donsol and various beaches and falls. Heavy rains may also provide difficulty in accessing the route of some nature-based tourism sites. Many of the country's agri-ecotourism sites are located in peripheral areas where infrastructures are poor and amenities are weak. Landslides and mudslides may not only threaten the operation of the sites but may discourage the tourists from visiting due to potential hazards along the way. Further, the short run-way and the incomplete facilities of Naga airport makes it harder to cope with the increasing intensity of rainfall as this causes more cancelation of flights. As the frequency of extreme events in next decades gets higher, the factors that aggravate the vulnerability of the community should then be addressed immediately. High and dry temperature can be exceedingly felt than the frequency of increased rainfall. This means that the adaptation measures should be more particular on addressing the temperature issues in the region.

\section{CONCLUSIONS}

The tourism vulnerability of nature-based attractions in the rural areas is generally high especially to sites where management and financial support are low as in the case of Calaguas Island. Poverty remains to be the major factor why vulnerability is high.

It must be noted that these climate variability and extreme events have occurred for several years already. What is interesting is the fact that the observed resiliency of the communities indicates that there is really a strong amount of experience in dealing with it. However, there seems to be a knowledge gap in addressing their "high vulnerability" rating in many aspects of tourism.

\section{RECOMMENDATIONS}

Proper Identification of Hazard Areas: Squatters are not only found in urban areas but in rural areas as well. For people who depend largely on farming and fishing, farm and coastal areas are the perfect sites for settling. However, these are also the same sites that are high risks and possible targets of disasters. The number of squatters in the Philippines is increasing exponentially as poverty worsens over time. People build houses where opportunities are seen. Ecotourism sites are not spared from this condition. The old cliché that says prevention is better than cure could somewhat ward off possible damages to life and property. A strict implementation of non-settling in danger zones should be executed. This would also mean proper identification and assessment of hazard areas in the sites every three to five years.

Multiple-Livelihood Engagement: As mentioned in the conclusion, poverty remains a major reason for high vulnerability. More often, poverty is associated with agriculture and vice-versa. Many households rely solely on farming or fishing as a means of livelihood. Agriculture is very much dependent on climate, so if there will changes in the climate, productivity is compromised. This will now endanger food, education, transportation, communication and shelter of the community where they could somehow get a portion of their strength for survival. But if people are given multiple options either as a gainful employment or 
micro-enterprise activities, the chance of being depressingly affected by climate change is narrowed down.

Massive Campaign of Climate Change Effects: Only a handful people in each community are aware of what climate change can do to them. Nevertheless, despite this awareness, no actions have been taken to prepare themselves from the consequences of climate change. Campaign should start not from the household heads but from the youngest to the oldest member. Training young minds is easier than old minds. Besides, a child remembers well than an adult. Children are good reminders to their older folks and can be great source of crusaders.

Pro-active Community DRRM Plans: Preparedness is manifested by the presence of a pro-active DRRM plan. This was not seen in any of the sites mentioned above. The LGU should assign a focal person who will be responsible in carrying out programmatic plan that will not

\section{ACKNOWLEDGMENT}

The author would like to thank the Commission of Higher Education for funding the research, the Central Bicol State University of Agriculture for the administrative and logistic support and to the communities in Calaguas Island, Bulusan Lake and Pecuaria Farm for making this research possible.

\section{REFERENCES}

[1] Community-Based Climate Vulnerability Assessment and Adaptation Planning: A Cook Islands Pilot Project. 2011. Submitted to Asian Development Bank. Publication Stock No. ARM114084

[2] Ehrlich, Richard. (2012) The Travel.cnn homepage. [Online]. Available:http://travel.cnn.com/explorations/escape/philippines/what s-problem-philippine-tourism-918924

[3] Parry L., et al. Climage Change 2007: Impacts, Adaptation and Vulnerability 2007.

[4] "Ranking of Municipalities in Support to Vulnerability Mapping of the Central Philippines Rural Development Project," Bureau of Soils and Water Management, Technical Report, 2012.

[5] Caraballo, Mayvelin U. (2013, May 14). Philippine tourism on the rise but tough competition from region. Manila Times. [Online]
Available: http://skift.com/2013/05/14/philippines-tourism-on-therise-but-tough-competition-from-region-report/

[6] Domingo, Ronnel W. (2013, February 25) Philippines joins push for Asean tourism. Philippine Daily Inquirer. [Online]. Available: www.business.inquirer.net/109205

[7] "Vulnerability and Impact of Climate Change on Major Tourism Attractions and Activities". Golder Associates Africa Ltd, South Africa. Submitted to Deutsche Geseilschaft fur Internationale Zusammenarbeit (GIZ). Report No.11613331-10989-2. 12. 2011.

[8] Schulze, Roland, et.al. Climate Change and Tourism in South Africa: A Basic Guideline for Vulnerability Assessment. R Golder Associates Africa Ltd, South Africa. Submitted to Deutsche Geseilschaft fur Internationale Zusammenarbeit (GIZ). Report No. 11613331-110263. March 2012.

[9] Wall, Geoffrey. 2007. "The Tourism Industry and its Adaptability and Vulnerability to Climate Change". Climate Change and Tourism - Assessment and Coping Strategies. pp.5-18

[10] Calgaro, Emma et.al. November 2009. Destination Vulnerability Assessment for Khao Lak, Thailand. Stockholm Environment Institute and Macquarie University

[11] Pulhin, Juan M. et.al. 2006, October. Vulnerability of Communities to Climate Variability and Extremes: Pantabangan-Carranglan Watershed in the Philippines. AIACC Working Papers, Washington, DC 20009 USA. [Online]. Available: www.aiaccproject.org

[12] The world population view website. [Online]. Available: http://worldpopulationreview.com/countries/the-philippinespopulation/

[13] Yusuf, Arief and Francisco, Herminia. January 2009. Climate change vulnerability mapping in Southeast Asia. Economy and Environment Program for Southeast Asia [Online] Available: http://css.escwa.org.lb/sdpd/1338/d2-5b.pdf

[14] Bennett, Charmian and McMichael Anthony. (2010, December 17). Non-heat related impacts of climate change on working populations. Glob Health Action v3i0.5640. [Online]. Available: http://www.ncbi.nlm.nih.gov/pmc/articles/PMC3009583/

[15] Climate Smart Agriculture Sourcebook, FAO UN, 2013

[16] Impacts of Climate Change on Biodiversity, Ecosystems, and Ecosystem Services. Technical Input to the 2013 National Climate Assessment. [Online]. Available: http://downloads.usgcrp.gov/NCA/ Activities/Biodiversity-Ecosystems-and-Ecosystem-ServicesTechnical-Input.pdf

[17] ITB World Travel Trends Report 2013/2014. IPK International. Submitted to ITB Berlin. [Online]. Available: http://www.itbberlin.de/media/itb/itb_media/itb_pdf/WTTR_Report_2014_Web.pdf

[18] Food Safety for Flooded Farms: In the aftermath of flooding, fruit and vegetable crops may pose a food safety risk. [Online]. Available: http://www.ext.colostate.edu/pubs/drought/food-safety-floodedfarms.pdf 